\title{
La ampliación de plazos (artículo 42.6 en relación con los artículos 47 y 49 de la LRJAP-PAC)
}

\author{
Santiago González-Varas Ibáñez \\ Catedrático de Derecho administrativo en la Universidad de Alicante \\ sago_va@yahoo.es \\ Recibido: 24 de diciembre de 2012 \\ Aceptado: 24 de mayo de 2013
}

Resumen

En este trabajo se pone de manifiesto una cierta inseguridad jurídica en un tema (tan transcendental en la práctica administrativa) como en el de la ampliación de plazos.

Palabras clave Plazos, procedimiento administrativo, caducidad, ampliación de plazos, prescripción, sanciones, urbanismo.

\section{The extension of deadlines}

\author{
Abstract \\ This paper highlights some legal uncertainty on an issue (as transcendental in administrative practice) as is the \\ extension of deadlines.
}

Key words

Administrative practice, procedure, deadlines. 


\section{PLANTEAMIENTO}

Parece oportuno abordar este tema ante la falta de claridad del mismo y lo frecuente de su aplicación práctica. En concreto, a continuación vamos a estudiar qué criterios mantiene la Ley 30/1992 de Régimen Jurídico de las Administraciones Públicas y del Procedimiento Administrativo Común, respecto de la ampliación de los plazos en el procedimiento administrativo, y, en especial, en cuanto a la posibilidad de ampliar el plazo de resolución del expediente, que es el supuesto que nos interesa.

En la Ley 30/1992, como excepción a la regla de la obligatoriedad de los plazos regulada en su artículo 47, nos encontramos dos preceptos que se refieren a la ampliación de los plazos: por una parte el artículo 42.6 y, por otra parte, el artículo 49, que reproducimos a continuación:

\section{Artículo 42.6:}

"Cuando el número de las solicitudes formuladas o las personas afectadas pudieran suponer un incumplimiento del plazo máximo de resolución, el órgano competente para resolver, a propuesta razonada del órgano instructor, o el superior jerárquico del órgano competente para resolver, a propuesta de éste, podrán habilitar los medios personales y materiales para cumplir con el despacho adecuado y en plazo.

Excepcionalmente, podrá acordarse la ampliación del plazo máximo de resolución y notificación mediante motivación clara de las circunstancias concurrentes y sólo una vez agotados todos los medios a disposición posibles.

De acordarse, finalmente, la ampliación del plazo máximo, éste no podrá ser superior al establecido para la tramitación del procedimiento.

Contra el acuerdo que resuelva sobre la ampliación de plazos, que deberá ser notificado a los interesados, no cabrá recurso alguno".

\section{Artículo 49:}

“1. La Administración, salvo precepto en contrario, podrá conceder de oficio o a petición de los interesados, una ampliación de los plazos establecidos, que no exceda de la mitad de los mismos, si las circunstancias lo aconsejan y con ello no se perjudican derechos de tercero. El acuerdo de ampliación deberá ser notificado a los interesados.

2. La ampliación de los plazos por el tiempo máximo permitido se aplicará en todo caso a los procedimientos tramitados por las misiones diplomáticas y oficinas consulares, así como a aquellos que, tramitándose en el interior, exijan cumplimentar algún trámite en el extranjero o en los que intervengan interesados residentes fuera de España.

3. Tanto la petición de los interesados como la decisión sobre la ampliación deberán producirse, en todo caso, antes del vencimiento del plazo de que se trate. En ningún caso podrá ser objeto de ampliación un plazo ya vencido. Los acuerdos sobre ampliación de plazos o sobre su denegación no serán susceptibles de recursos". 
Tras la lectura de ambos artículos, lo primero que se observa es que el artículo 42.6 se refiere a la ampliación del plazo máximo para resolver el procedimiento, mientras que el artículo 49 recoge el supuesto de ampliación de plazos en general para los distintos trámites del procedimiento.

También es claro que la ampliación otorgada mediante ambos artículos difiere: mientras que el plazo para resolver se puede ampliar como máximo hasta un plazo igual al de la tramitación del procedimiento, el artículo 49 prevé una ampliación máxima de la mitad del plazo cuya ampliación se solicita.

Ambos artículos coinciden en la irrecurribilidad del acuerdo otorgando o denegando la ampliación.

En lo que difieren especialmente es en que mientras la ampliación de plazos de los trámites del artículo 49 precisaría de una motivación por referencia a hechos y fundamentos jurídicos (según el artículo 54.1.e LRJAP-PAC), el acuerdo para la ampliación del plazo para resolver del artículo 42.6 es más excepcional, pues solamente se podrá adoptar cuando sea la única posibilidad existente una vez se hayan habilitado todos los medios humanos y materiales posibles y ni aun así sea posible resolver en plazo, dado el número de personas afectadas.

Se estudian a continuación los criterios del Tribunal Supremo respecto de los artículos de la Ley 30/1992 citados y las sentencias de los Tribunales Superiores de Justicia respecto de dichos artículos de la LRJAP-PAC. Estamos ante una cuestión en la que puede interferir la aplicación de una norma autonómica con regulación propia en la materia, lo que no es inhabitual en la urbanística, previendo la posible ampliación del plazo máximo para resolver de procedimientos sancionadores (por ejemplo, artículo 243 de la Ley Urbanística Valenciana, o 247 de la LS de la Región de Murcia, etc.)'

\section{EXCEPCIONALIDAD EN CUANTO A LA APLICACIÓN DEL 42.6 LRJAP-PAC}

En la STS de 24 de enero de 2011 (recurso de casación número 2542/2008) se desestima el recurso de casación interpuesto por la Abogacía del Estado contra la sentencia dictada con fecha 1 de febrero de 2008 por la Sala de lo Contencioso-Administrativo de la Audiencia Nacional, al entender que la motivación exigible para acordar la ampliación del plazo máximo para resolver debería referirse a las circunstancias contempladas en el artículo 42.6, que, por otra parte, han de ser interpretadas res-

1 En la doctrina, nos remitimos al estudio de estos artículos por J. González Pérez, Comentarios a la Ley de Régimen jurídico de las Administraciones Públicas y del Procedimiento Administrativo Común, Tomo I, 4 a edición, Madrid 2007, pp. 1204 y ss. y pp. 1450 y ss.; más recientemente M. J. Gallardo Castillo, Régimen jurídico de las Administraciones Públicas y del Procedimiento Administrativo Común, Madrid, 2010, pp. 223 y ss. 
trictivamente en el ámbito del procedimiento sancionador y sentando que la consecuencia que se deriva de la nulidad del acuerdo ampliatorio por no respetar tales circunstancias es la caducidad del procedimiento sancionador:

"La Administración invoca el artículo 42.6 para acordar la ampliación del plazo por tiempo de un mes, sin embargo el apartado segundo del citado párrafo 6 se refiere a un específico supuesto definido en el apartado primero, consistente en "Cuando el número de solicitudes formuladas o las personas afectadas pudiera suponer un incumplimiento del plazo máximo de resolución..." supuesto en el que el órgano competente para resolver podrá habilitar los medios personales y materiales para cumplir con el despacho adecuado y en plazo, y sólo para este supuesto, excepcionalmente podrá acordarse la ampliación del plazo máximo de resolución y notificación mediante la motivación clara de las circunstancias concurrentes y sólo una vez agotado todos los medios a disposición posibles (apartado segundo del párrafo 6).

Así las cosas, el procedimiento sancionador, del que trae causa este recurso, no puede incluirse en tal apartado ni por el número de solicitudes ni por las personas afectadas y, por tanto, tampoco puede aplicarse la excepcionalidad prevista en el apartado segundo.

A mayor abundamiento el instructor no realizó actividad desde el 14 de febrero 2005, que Terra presentó escrito de alegaciones, hasta el 3 de noviembre del mismo año. $Y$, en todo caso, la motivación exigible para acordar la ampliación del plazo debería referirse a las circunstancias contempladas en el que tantas veces citado artículo 42.6, sin embargo la Administración motiva tal ampliación exclusivamente en la necesidad de garantizar que dispone de todo el tiempo que resulte necesario para analizar y valorar las alegaciones que presente el imputado en trámite de audiencia, $y$, en concreto, la especial consideración de que el plazo para dictar el procedimiento terminaba el 13 de diciembre y el instructor aún no había culminado su actividad por la complejidad que supuso efectuar una correcta valoración del elemento subjetivo de la culpa del imputado y la correspondiente cuantificación de la sanción a proponer. Motivación que se fundamenta en causas que, como ya hemos indicado, no pueden incluirse en ninguno de los supuestos tasados que establece la Ley y el Reglamento, supuestos que deben ser interpretados restrictivamente en el ámbito del procedimiento sancionador.

Siendo ello así, la ampliación del plazo que acordó la Administración carece de apoyatura legal o reglamentaria y, por tanto, la notificación de la resolución impugnada se produjo una vez vencido el plazo máximo de un año previsto el artículo 58 de la Ley General de Telecomunicaciones, aun computando la ampliación del plazo de 15 días que a solicitud de Terra acordó la CMT.

La consecuencia que se deriva de la notificación de la resolución sancionadora una vez vencido el plazo máximo, conforme al artículo 44.2 de la Ley 30/1992, es la caducidad del procedimiento sancionador y la estimación del presente recurso sin necesidad de entrar en el análisis de los restantes motivos de impugnación aducidos." 
La STS de 22 de septiembre de 2009 confirma la estimación del recurso por indebida aplicación del artículo 42.6 de la Ley 30/1992 por parte de la Administración autonómica canaria para ampliar el plazo máximo para resolver, aun estando justificada la resolución de ampliación en la existencia de un gran número de solicitudes y en que el Tribunal de Defensa de la Competencia agotó cerca de tres de los seis meses de que se disponía para resolver. En esta sentencia se recoge la doctrinal jurisprudencial respecto de este artículo 42.6, en el sentido de que la solución de la ampliación del plazo no puede concebirse como una posibilidad extrema en supuestos absolutamente excepcionales, sino como una posibilidad admisible cuando la Administración no encuentre otra forma razonable para el cumplimiento del plazo y lo justifique adecuadamente:

"La Ley prevé, en consecuencia que ante la acumulación de un número excesivo de asuntos a resolver se habiliten los medios personales y materiales necesarios para resolver en plazo dichos asuntos. Y que, excepcionalmente, "agotados todos los medios a disposición posibles", puede acordarse la ampliación del plazo. Esta Sala ya se ha pronunciado en casos análogos y ha interpretado esta previsión legal en el sentido de que basta una justificación clara y real de la dificultad para resolver en el plazo ordinario para que sea admisible la ampliación del mismo. Esto es, que la solución de la ampliación del plazo no puede concebirse como una posibilidad extrema en supuestos absolutamente excepcionales, sino como una posibilidad admisible cuando la Administración no encuentre otra forma razonable para el cumplimiento del plazo y lo justifique adecuadamente (Sentencias de 10 de julio de 2008 y 4 de marzo de 2009). Así, hemos dicho:

"QUINTO.-En el segundo motivo de casación 'Telefónica de España, SAU' discrepa de las apreciaciones del tribunal de instancia en cuanto a los dos acuerdos relativos al plazo para resolver. A su juicio, coincidente con el que ya sostuvo en la demanda, a) el expediente no tenía la complejidad necesaria para que fuera necesario ampliar en tres meses su tramitación y, además, había otros medios alternativos para conseguir el mismo fin; y b) el acuerdo de solicitar determinados informes no podía tener efecto suspensivo.

A) En lo que se refiere al primer argumento, la tesis de la recurrente insiste en que el acuerdo de ampliación del plazo carecía de una motivación objetiva y razonable y que no concurrían en él los presupuestos objetivos para aplicar el artículo 42.6 de la Ley 30/1992. Norma que permite, excepcionalmente, acordar la ampliación del plazo máximo de resolución y notificación con los únicos requisitos de que los acuerdos correlativos tengan una 'motivación clara de las circunstancias concurrentes' y que hayan sido previamente 'agotados todos los medios a disposición posibles'.

La alegación de 'Telefónica de España, SAU' no puede prosperar. Basta leer el contenido de aquella decisión para corroborar tanto su 'claridad' como la razonabilidad de su justificación. Las circunstancias objetivas del voluminoso expediente tramitado (que culmina en un acuerdo final de 312 páginas) requerían el análisis y la verificación de datos relativos a numerosas empresas y terminales, tarea cuya duración en el tiempo razonablemente podía sobrepasar la 'normal' de otros expedientes sancionadores, todo lo cual legitimaba la ampliación. 
No cabe, por lo demás, afirmar que el organismo regulador dejara de habilitar otros medios alternativos. Siendo cierto que el órgano administrativo ha de agotar todos los medios a su alcance antes de decretar la ampliación del plazo máximo de duración del procedimiento, y aun cuando la Sala de instancia no se haya referido a este extremo de modo expreso en su sentencia, nada hay que demuestre lo contrario. La recurrente no llega a identificar qué otros medios preferentes hubiera debido emplear el organismo regulador, dentro de la medida de sus posibilidades y recursos humanos, antes de acudir al mecanismo ampliatorio del plazo. [...]" (fundamento de derecho quinto de la Sentencia de 4 de marzo de 2009).

En el caso de autos la razón para la aplicación de la ampliación del plazo está claramente determinada, el número de expedientes -cuantificándose incluso los del año, a los que había que sumar los de años anteriores todavía en tramitación-, y la necesidad de recabar informes externos, cuya mayor o menor rapidez de tramitación no depende directamente del órgano que ha de resolver. Y, en cuanto a la utilización de otros medios, es verdad que, como la Sala de instancia señala, la Orden no especifica si se pudo arbitrar o no algún otro medio extraordinario -tan sólo se afirma que "se consideran agotados todos los medios a disposición posibles"-, y solamente a posteriori se ha aducido la imposibilidad de trasladar personal a la unidad administrativa afectada. Sin embargo, tampoco la empresa solicitante de la licencia sugiere ninguna otra posibilidad de medios extraordinarios para el puntual cumplimiento del plazo ordinario para resolver. Por otra parte, debe también admitirse que si la Administración ha de hacer frente a una excesiva acumulación de expedientes de cualquier género tiene que enfocar el cumplimiento regular de los plazos de una manera global respecto a todos ellos, por encima de las incidencias de cada expediente en concreto, por lo que la ampliación del plazo se presenta como una respuesta extraordinaria razonable para el conjunto de tales expedientes.

Como consecuencia de todo lo anteriormente expuesto se deriva que al no haber apreciado que la ampliación del plazo para resolver era conforme con la previsión del artículo 42.6 de la Ley 30/1992, de 26 de noviembre, por estar debida y suficientemente razonada, se ha producido una infracción del mismo que conlleva la estimación del motivo y del recurso de casación."

Finalmente puede citarse en esta misma línea la STS de 15 de febrero de 2013 RJ 3193.

\section{LA AMPLIACIÓN DEL PLAZO EN EL MARCO DEL ARTÍCULO 49 DE LA LEY $30 / 1992$}

Como vamos a ver en la siguiente jurisprudencia, el TS entiende que el artículo 49 LRJAP-PAC es aplicable a la ampliación del plazo máximo para resolver, exigiendo una motivación no tan rígida como la del artículo 42.6 LRJAP-PAC y como consecuencia de ello aquel precepto tiene un efecto ampliatorio del plazo para resolver no tan extenso como el del citado artículo 42.6. Se observan al respecto contradicciones argumentales, ya que en cambio para los Tribunales Superiores de Justicia el artículo

34 que para dicho fin ya está previsto expresamente el artículo 42.6. 
Así, según la STS de 20 de marzo de 2007 es posible acordar la ampliación del plazo máximo para resolver un procedimiento sancionador en virtud del artículo 49.1 LRJAP-PAC, siendo el efecto de la ampliación diferente al generado por el artículo 42.6 de la misma Ley, pues también las condiciones de aplicación de ambos preceptos son diferentes:

"No puede aceptarse la interpretación realizada por la actora respecto a que la posibilidad de ampliación de plazos contemplada en el artículo 49 de la Ley 30/1992 no pueda ser aplicada al plazo máximo de duración de un procedimiento. Ni tal exclusión se establece de manera directa y expresa en el precepto señalado (a diferencia de lo que ocurría con anterioridad a la reforma de la Ley operada en 1999), ni existen razones para deducirla en un análisis sistemático de la Ley. En efecto, la regulación específica para ampliar el plazo máximo de resolución y notificación de un procedimiento en el artículo 42.6 no obsta a la aplicación de la previsión genérica del artículo 49 al mismo supuesto, teniendo ambos preceptos un alcance diferente. Así, las condiciones para la aplicación del supuesto específico del artículo 42.6 son más estrictas y la ampliación puede alcanzar hasta un lapso de tiempo igual al del plazo máximo del procedimiento (artículo 42.6, párrafo tercero); por el contrario, la ampliación posible en aplicación de la previsión genérica del artículo 49 puede ser acordada por el propio órgano instructor y sólo puede llegar hasta la mitad del plazo ampliado (apartado 1).

En consecuencia, siendo conforme a derecho la ampliación del plazo para resolver decidida por el instructor en su acuerdo de 5 de noviembre de 2004, debe rechazarse la alegación de caducidad formulada por la recurrente".

Según las Sentencias de la Audiencia Nacional de 20 de enero de 2010 y de 17 de junio de 2009 se permite la ampliación del plazo máximo para resolver en virtud del artículo 49 LRJAP-PAC, pues en la materia objeto del recurso existe una disposición que expresamente remite al artículo 49 para la ampliación de los plazos (tanto parciales como totales), entendiéndose justificada la ampliación del plazo por la complejidad del expediente:

"SEGUNDO.-Previamente al análisis de la cuestión de fondo que se nos somete hemos de resolver la alegada caducidad del expediente.

La recurrente sostiene que la Resolución se dictó cuando ya el expediente había caducado.

Queda admitido por la demandante que el expediente se inició el 11 de enero de 2007 y que concluyó el 16 de junio de 2008, si bien existe un acuerdo de ampliación de actuaciones por seis meses dictado el 19 de diciembre de 2007 y notificado a la interesada, dada la complejidad del expediente administrativo. El plazo para concluir el expediente es de un año, esto no se discute, y habría un plazo más de seis meses en virtud de la ampliación.

El artículo 2 del Real Decreto 2119/1993 establece:

“1. El plazo total para tramitar y resolver el procedimiento sancionador será de un año a contar desde la adopción del acuerdo de iniciación. En el caso de seguirse el procedimiento simplificado previsto en el artículo 10 dicho plazo será de cuatro meses. 
2. Tanto el plazo total, como los parciales previstos en este Real Decreto para los distintos trámites, podrán ser ampliados según lo previsto en el apartado 1 del artículo 49 de la Ley 30/1992 de 26 de noviembre, de Régimen Jurídico de las Administraciones Públicas y del Procedimiento Administrativo Común, debiéndose notificar la decisión adoptada a los interesados."

El artículo 49.1 de la Ley 30/1992, en su redacción dada por Ley 4/1999, establece:

“1. La Administración, salvo precepto en contrario, podrá conceder de oficio o a petición de los interesados, una ampliación de los plazos establecidos, que no exceda de la mitad de los mismos, si las circunstancias lo aconsejan y con ello no se perjudican derechos de tercero. El acuerdo de ampliación deberá ser notificado a los interesados."

Pues bien, la Administración acordó la ampliación en base a la complejidad del expediente, causa ésta contemplada en el artículo 49.1 citado, al señalar que la ampliación puede acordarse si "las circunstancias lo aconsejan"."

En sentido similar puede también consultarse la SAN de 31 de marzo de 2000 RJCA 963.

\section{SENTENCIAS DE LOS TRIBUNALES SUPERIORES DE JUSTICIA SEGÚN LAS CUALES, AL EXISTIR UNA PREVISIÓN EXPRESA DE AMPLIACIÓN DE PLAZO EN LA LEGISLACIÓN AUTONÓMICA, SE APLICA ÉSTA}

En la casuística encontramos situaciones en las que, por existir en la legislación autonómica un criterio en materia de ampliación de plazos, se aplica este criterio directamente, en vez de las reglas que hemos estudiado por referencia a los artículos 42 y 49 de la LRJAP-PAC 30/1992, eso sí, exigiendo una motivación más allá de la alegación de circunstancias genéricas.

La STSJ de la Región de Murcia de 23 de abril de 2010 expresamente afirma que, al prever la Ley urbanística autonómica un artículo sobre la ampliación del plazo máximo para resolver, no hace falta acudir a la Ley 30/1992 (y señala que no se precisa o no cabe acudir al artículo 49 de dicha norma estatal, pues a su juicio no está previsto para los procedimientos sancionadores -a diferencia de la postura mantenida por el TS que hemos plasmado supra-). Según esta sentencia de 23 de abril de 2010 la ampliación del plazo máximo para resolver es una medida excepcional y, por tanto, sólo causas también excepcionales y debidamente justificadas, examinadas en el contexto de las actuaciones seguidas, pueden justificar la ampliación. Asimismo, se sostiene en esta sentencia que una motivación genérica en estos casos puede considerarse como una falta de motivación; y que la falta de diligencia de la Administración a la hora de tramitar el expediente sancionador no permite acudir posteriormente al instituto de la ampliación del plazo máximo para resolver:

"La cuestión debatida en la presente apelación se centra en la conformidad o no a derecho del acuerdo de ampliación del plazo para resolver y notificar la resolución 
del procedimiento sancionador, y, consecuentemente, si se ha producido o no la caducidad del mismo. Según consta en el expediente administrativo, en fecha 15 de enero de 2007 se acordó por el Teniente de Alcalde de Urbanismo ampliar en tres meses el plazo para resolver y notificar el procedimiento sancionador. Se argumenta en dicho acto que, de conformidad con el artículo 247 de la Ley del Suelo de la Región de Murcia, Texto Refundido aprobado por Decreto Legislativo 1/2005, en relación con el artículo 49 de la Ley 30/1992, el plazo máximo para notificar la resolución es de un año, ampliable por tres meses. $Y$ se justifica la ampliación del plazo en los siguientes términos: "... teniendo en cuenta que las circunstancias aconsejan en estos casos la ampliación del plazo, por tratarse de procedimientos cuya tramitación requiere la emisión de diversos informes técnicos y dada la cantidad de asuntos pendientes en esta Sección, y estando próximo el vencimiento del plazo para notificar dicha resolución...".

El artículo 49.1 de la Ley 30/1992 dispone que "La Administración, salvo precepto en contrario, podrá conceder de oficio o a petición de los interesados, una ampliación de los plazos establecidos, que no exceda de la mitad de los mismos, si las circunstancias lo aconsejan y con ello no se perjudican derechos de tercero. El acuerdo de ampliación deberá ser notificado a los interesados." Es evidente que esta norma no resulta de aplicación en los procedimientos sancionadores, como se razona en la sentencia de instancia, sino que se trata de la posibilidad de ampliar plazos en general, y por ello está previsto que pueda acordarse a petición de los interesados. En todo caso, tampoco era necesario acudir a la Ley 30/1992 para la ampliación del plazo, pues esta posibilidad está expresamente prevista en la Ley del Suelo de la Región de Murcia, que en su artículo 247, al regular la caducidad del procedimiento sancionador, dispone en su apartado 1 que "El plazo máximo en que debe notificarse la resolución expresa del procedimiento sancionador será de un año contado desde la fecha del acuerdo de iniciación, ampliable, como máximo, por tres meses, mediante acuerdo del órgano que inició el procedimiento. Contra este acuerdo de ampliación no cabrá recurso alguno." $Y$ añade en el apartado 2 que transcurridos los citados plazos, en sus respectivos casos, sin que se haya producido la notificación de la resolución, se producirá la caducidad del procedimiento.

En la sentencia $n^{\circ} 972 / 2005$ que se invoca por la parte apelante, dictada por esta Sala en fecha 23 de diciembre de 2005 , se contempla también la validez de un acuerdo de ampliación del plazo adoptado con aplicación del artículo 247 de la Ley 1/2001, del Suelo de la Región de Murcia. Dicha sentencia no admite como causa, por sí sola, para la ampliación la existencia de un elevado número de expedientes sancionadores a tramitar y resolver, sino que indica que ante tal circunstancia debió hacerse así constar en el acuerdo de ampliación, de modo que el interesado pueda conocer y el órgano jurisdiccional enjuiciar, en su caso, la legalidad de la medida. Y si bien se razona que "pueden existir diversas causas para la demora en la resolución del expediente, como son la existencia de un elevado número de expedientes sancionadores a tramitar y resolver...", en ningún momento se pronuncia sobre si esas causas justificaron en el caso concreto la ampliación del expediente. Es evidente que sobre la cuestión que se plantea no pueden hacerse pronunciamientos generales, como pretende el Ayuntamiento demandado, sino que ha de estarse a las circunstancias del caso concreto. $Y$ en el presente supuesto tales circunstancias han sido detalladamente expuestas por el Juzgador de instancia, y tras su valoración ha llegado a la conclusión de que no procedía la ampliación del plazo máximo para resolver. Dicho criterio es compartido por esta Sala, pues las razones que se expresan en el acuerdo 
son, en primer lugar, tan genéricas que podría concluirse que existe también en este caso una falta de motivación. Pero, aun considerando motivada formalmente la ampliación, la tramitación que se siguió en el procedimiento pone de manifiesto que hubo una demora injustificada en la resolución"”

En conclusión, según este criterio mantenido por el TSJ de Murcia, no es preciso acudir a la Ley 30/1992 si la ley urbanística autonómica prevé un criterio sobre ampliación del plazo del duración del procedimiento, pero la ampliación de tal plazo no será procedente si no se motiva adecuadamente o si concurre falta de diligencia debida en la tramitación en general del procedimiento.

\section{SENTENCIAS DE LOS TRIBUNALES SUPERIORES DE JUSTICIA QUE REAFIRMAN EL CARÁCTER EXCEPCIONAL DEL ARTÍCULO 42.6 DE LA LRJAP-PAC 30/1992 Y QUE, SIN EMBARGO, NIEGAN LA APLICABILIDAD DEL ARTÍCULO 49 DE LA LRJAP-PAC 30/1992 PARA LA AMPLIACIÓN DEL PLAZO DE RESOLUCIÓN DE LOS PROCEDIMIENTOS, A DIFERENCIA DEL CRITERIO DEL TS SUPRA EXPUESTO}

Este criterio lo encontramos, asimismo, en las sentencias existentes, seguramente porque no existe previsión expresa en norma autonómica sobre ampliación

2 Añade la sentencia: «Así, es de observar que la sentencia del Juzgado de lo Penal $n^{\circ} 3$ de Murcia se recibió en el Ayuntamiento el día 24 de marzo de 2006, fecha en que pudo reanudarse el procedimiento. Desde la misma hasta que se llevó a cabo la siguiente actuación (7 de agosto), transcurrieron casi cinco meses sin que conste causa alguna que justificara dicha inactividad. Y la citada actuación consistió en una comunicación interior de la Técnico de Administración General al Jefe del Servicio Técnico de Disciplina Urbanística remitiéndole el expediente para que "urgentemente" emitiera el informe de valoración e indicara si los actos eran o no susceptibles de legalización, plazo para el restablecimiento de la legalidad, en su caso, coste del mismo e informe sobre adaptación al PGOU. El día 8 de agosto se solicitó por el Servicio Técnico de Disciplina Urbanística informe a la Unidad de Inspección sobre la visita a las obras, haciendo constar que era necesario a la "mayor urgencia (en el plazo máximo de 1 semana...)". No obstante, el informe se emitió en fecha 14 de septiembre. Y el informe sobre afectación de las obras por la adaptación del Plan General a la Ley del Suelo se emitió el día 10 de octubre. El día 11 de enero de 2007 se nombró instructora en el expediente, notificándose al interesado el día 18 de enero. La resolución siguiente fue la de ampliación del plazo. Como puede verse, sólo se emitieron dos informes durante el tiempo que transcurrió entre la recepción de la sentencia penal y la resolución de ampliación del plazo, por lo que, como se señala en la sentencia apelada, en casi cinco meses se realizaron únicamente esos informes y el acto de nombramiento de la Instructora y su notificación. Y con posterioridad a la ampliación del plazo consta el Decreto ordenando el restablecimiento de la legalidad urbanística, su notificación al recurrente, la propuesta de resolución y su notificación al interesado, las alegaciones de éste, dos informes técnicos y la resolución sancionadora que se dictó el día 19 de abril y su notificación. Es decir, que en el plazo de cuatro meses se realizaron muchos más trámites que en los casi diez meses que transcurrieron entre que se recibió la sentencia penal y se acordó la ampliación del plazo. Es patente, pues, que antes de dicha ampliación hubo una demora en la realización de los trámites procedimentales, y no puede ampararse la misma en la alegada cantidad de asuntos pendientes en la Sección de Disciplina Urbanística, máxime cuando no se justifica que ese retraso obedezca al elevado número de asuntos. La ampliación del plazo para resolver es una medida excepcional, pues supone otorgar a la Administración un tiempo adicional para cumplir con su obligación de resolver un procedimiento y notificar la resolución dentro del plazo establecido legalmente. Por tanto, sólo causas también excepcionales y debidamente justificadas, examinadas en el contexto de las actuaciones seguidas, pueden justificar la ampliación, justificación que no se aprecia en el presente caso por lo antes expuesto, lo que determina que efectivamente, y como así ha resuelto el Juzgador de instancia, haya de apreciarse la caducidad del expediente». 
del plazo máximo para resolver (a diferencia del criterio del TSJ murciano que acabamos de reseñar), bien por simple casuística.

La STSJ de Andalucía (Sevilla) de 1 de febrero de 2010 afirma que el artículo 49 LRJAP-PAC sólo habla de plazos y no de términos, de modo que la ampliación del plazo máximo de duración del procedimiento sólo puede adoptarse al amparo del art. 42.6, siendo dicha ampliación excepcional, acordada con una motivación clara de las circunstancias concurrentes y sólo una vez agotados todos los medios a disposición posibles:

“CUARTO.-Examinado lo actuado comprobamos que el Acuerdo de Inicio es de fecha 30 de septiembre de 2005 y la Resolución Sancionadora se notificó el 24 de noviembre de 2006.

Sin embargo, antes de que transcurriera el plazo de diez meses estipulado al afecto en el Anexo I de la Ley 9/2001, se procedió a notificar la ampliación del antecitado plazo.

La cuestión consiste en determinar si al acordar la ampliación se actuó, o no, conforme a Derecho.

QUINTO.-Este mismo Tribunal, en Sentencia de 30 de septiembre del año 2008, ha manifestado que:

El artículo 44.2 de la Ley 30/1992 dispone "En los procedimientos en que la Administración ejercite potestades sancionadoras o, en general, de intervención, susceptibles de producir efectos desfavorables o gravamen, se producirá la caducidad"... cuando haya vencido el plazo máximo establecido sin que se haya dictado y notificado la resolución expresa. Este plazo de conformidad con el Anexo I apartado 1.1.1 de la Ley 9/2001 es de diez meses.

El procedimiento sancionador se inició el 30 de septiembre de 2005 habiéndose dictado la Orden que pone fin al mismo e 7 de noviembre de 2006 , notificada el 24 de noviembre de 2006. El 20 de junio de 2006, se acordó una ampliación del plazo máximo de resolver de cinco meses al amparo de los arts. 42.6 y 49.3 de la Ley 30/1992. En atención a dicha ampliación en principio la resolución se había dictado y notificado dentro de plazo. Se ha de resolver, no obstante, si dicha ampliación del plazo era conforme a Derecho.

(...) Una interpretación conjunta y sistemática de ambos preceptos lleva a la conclusión de que el art. 49 sólo habla de plazos y no de términos, de modo que la ampliación del plazo máximo de duración del procedimiento sólo puede adoptarse al amparo del art. 42.6. El art. 49 se refiere únicamente a la posibilidad de ampliar los plazos desde el punto de vista intraprocesal, o sea, los fijados para evacuar los diversos trámites dentro del procedimiento en su conjunto, pero no a la ampliación del procedimiento.

Carece de sentido, por tanto la mención en la resolución de ampliación efectuada al art. 49.3 de la Ley 30/1992. El art. 42.6, como se ha indicado, recoge la posibili- 
dad de la ampliación del plazo de duración del procedimiento, ahora bien dicha ampliación como se indica en el precepto ha de ser excepcional, con motivación clara de las circunstancias concurrentes y sólo una vez agotados todos los medios a disposición posibles.

La resolución de ampliación justifica la decisión, en haberse solicitado la apertura del período probatorio obligándose a realizar más trámites, y en la necesidad de elevar el procedimiento al Consejero, por ser el órgano competente para el dictado de la resolución. Dichos motivos de ampliación, no se encuentran amparados en el art. 42.6. No suponen ninguna circunstancia excepcional en la tramitación de un procedimiento sancionador, sino exclusivamente la tramitación ordinaria del mismo. Siendo normal en todo procedimiento sancionador que se acuerde la apertura de un periodo probatorio, de conformidad con el Real Decreto 1398/1993. E igualmente, en ningún caso, puede entenderse como excepcional la remisión del procedimiento al órgano competente para que dicte la resolución.

No habiéndose justificado por la Administración la concurrencia de circunstancia excepcional alguna, ha de anularse la ampliación de plazo, lo que supone que la resolución se ha dictado fuera del plazo de diez meses legalmente establecido, debiéndose estimar el recurso por caducidad del procedimiento. Esto impide el enjuiciamiento de la cuestión de fondo que queda imprejuzgada, porque la Administración puede iniciar nuevo expediente donde se respeten los plazos para resolver, siempre que no se haya producido la prescripción".

En sentido idéntico a la anterior, la STSJ de Andalucía (Sevilla) de 16 de septiembre de 2008: la ampliación del procedimiento se efectuó por parte de la Administración aplicando el art. 49 de la Ley 30/1992 y sin ningún tipo de motivación de las razones por las que se procedía a dicha ampliación, lo cual era doblemente inadecuado y contrario a Derecho. Si se pretendía la ampliación del plazo del procedimiento, razona el Tribunal, se debía haber acudido a la posibilidad excepcional del art. 42.6, pero debían haberse motivado las razones de la ampliación, con indicación de la imposibilidad de resolver en plazo pese a haberse utilizado y agotado todos los medios a disposición de la Administración.

La STSJ de Cataluña de 14 de julio de 2006 señala que el artículo 49 no es aplicable a una ampliación del plazo máximo para resolver, por existir regulación al respecto en el artículo 42.6, el cual, a su vez, contiene una posibilidad excepcional de ampliación de la duración máxima del procedimiento, debiendo rechazarse que sea utilizada como una prórroga rutinaria y generalizada:

"En el presente supuesto, la Administración demandada pretendió soslayar, $a b$ initio, la limitación legal en cuanto a la duración máxima del procedimiento, al amparo de dos preceptos legales, a saber:

El art. 122 ("Criterios de graduación" de las sanciones) de la Ley 27/1992, de 24 de noviembre, a tenor de cuyo párrafo 2: "Se aplicarán analógicamente, en la medida de lo posible y con las matizaciones y adaptaciones que exija la peculiaridad del sector administrativo de que se trata, las reglas penales sobre exclusión de la anti- 
juridicidad y de la culpabilidad, sin perjuicio de atender, a idénticos efectos, a otras circunstancias relevantes en dicho sector".

Y el art. 42.6 de la Ley 30/1992, de 26 de noviembre, conforme al cual: "Cuando el número de las solicitudes formuladas o las personas afectadas pudieran suponer un incumplimiento del plazo máximo de resolución, el órgano competente para resolver, a propuesta razonada del órgano instructor, o el superior jerárquico del órgano competente para resolver, a propuesta de éste, podrán habilitar los medios personales y materiales para cumplir con el despacho adecuado y en plazo. Excepcionalmente, podrá acordarse la ampliación del plazo máximo de resolución y notificación mediante motivación clara de las circunstancias concurrentes y sólo una vez agotados todos los medios a disposición posibles. De acordarse, finalmente, la ampliación del plazo máximo, éste no podrá ser superior al establecido para la tramitación del procedimiento.

Contra el acuerdo que resuelva sobre la ampliación de plazos, que deberá ser notificado a los interesados, no cabrá recurso alguno".

CUARTO.-Poniendo en relación el supuesto de hecho objeto del procedimiento sancionador, esto es, la infracción imputada a un único responsable, domiciliado en Barcelona, de un hecho sin ninguna complejidad, con las normas legales de cobertura de la pretensión administrativa de prolongar el plazo hábil de resolución del procedimiento, resulta patente la improcedencia de dicha pretensión, por cuanto :

a) En lo que se refiere a la invocación del transcrito art. 122.2 de la Ley 27/1992, la "peculiaridad" y las "circunstancias relevantes" del sector que menciona el precepto se relacionan con los criterios de graduación de las sanciones y no -en absoluto- con la posibilidad de prolongar la tramitación de los procedimientos, supuesto que prevé el art. 3.2 del Anexo II del RD 1772/1994, de 5 de agosto, anudado a la ampliación de plazos contemplada en el art. 49.2 de la Ley 30/1992, "siempre que los presuntos responsables residan en el extranjero o cuando, residiendo en España, fuera necesario cumplimentar algún trámite en el extranjero", no siendo el caso ; y

b) En cuanto a la previsión del art. 42.6 de la Ley 30/1992, no concurre en el supuesto ninguna circunstancia excepcional que justifique la aplicación del precepto, ni se contiene en la resolución de incoación la "motivación clara" que aquél exige, siendo que, tal como pone de manifiesto la Sentencia del TSJ de La Rioja de 2 de mayo de 2002, rec. 315/2001, "debe rechazarse que esta posibilidad excepcional de ampliación de plazo sea utilizada como una prórroga rutinaria y generalizada, mediante el uso de fórmulas generales y estereotipadas, sin hacer mención al caso concreto, supuesto este último para el que se introdujo exclusivamente el precepto analizado" (en el mismo sentido, SS de los TSJ de Castilla y León, sede de Burgos, de 4 de septiembre de 2003, rec. 578/2002 ; del País Vasco de 1 de junio de 2005, rec. 2264/2003; y de Galicia de 30 de junio de 2005, rec. 5040/2002).

Invocado por último por la Abogacía del Estado, en el escrito de contestación a la demanda, el art. 49 de la Ley 30/1992, con arreglo a cuyo párrafo 1 “la Adminis- 
tración, salvo precepto en contrario, podrá conceder de oficio o a petición de los interesados, una ampliación de los plazos establecidos, que no exceda de la mitad de los mismos, si las circunstancias lo aconsejan y con ello no se perjudican derechos de tercero", no cabe su aplicación por existir un precepto específico referido a la ampliación del plazo para resolver, cual es el art. 42.6 de la misma Ley, y además, esa indebida aplicación perjudicaría a tercero interesado en la perención del procedimiento (al respecto, STSJ de Madrid de 16 de febrero de 2002, rec. 89/2000), y en cualquier caso, el precepto contempla una prórroga máxima de la mitad del plazo, que aquí, a partir de los seis meses previstos en el art. 42.2 de la Ley 30/1992, alcanzaría a nueve meses, insuficientes para evitar la caducidad alegada.

Procede por cuanto antecede acoger el motivo de impugnación articulado en la demanda de este recurso contencioso, y apreciar la concurrencia de caducidad en el procedimiento administrativo seguido contra el actor, siendo por ende anulable la resolución sancionadora que le puso fin, puesto que debió de acordarse el archivo, todo ello con arreglo a los arts. 44.2, 63.1 y concordantes de la Ley 30/1992, de 26 de noviembre".

La STSJ Comunidad de Madrid de 16 de febrero de 2002 se refiere al carácter excepcional de la ampliación del artículo 42.6 de la Ley 30/1992 y a la no aplicabilidad del artículo 49 al supuesto de hecho por perjudicar a terceros la citada ampliación del plazo para resolver:

"Los Vicerrectores demandados entienden que este precepto de ampliación de plazos no es aplicable a este supuesto, pues establece de forma tajante que solo se permite mientras no perjudique a terceros, provocándoles a ellos en este caso claros perjuicios.

En consecuencia, nuestro primer punto de examen es este precepto interrelacionado con el 42 de la misma Ley, y su posibilidad de aplicarlos en un procedimiento especial como es el de lesividad, en el que una Administración pública, en este caso la UNED declara lesivo para el interés público un acto dictado por ella, a efectos de incoar un proceso contencioso-administrativo cuyo objeto es la anulación.

El artículo 49 establece que "La Administración salvo precepto en contrario, podrá conceder de oficio o a petición de los interesados, una ampliación de los plazos establecidos, que no exceda de la mitad de los mismos, si las circunstancias lo aconsejan y con ello no se perjudican derechos de tercero". Este precepto que habla de plazos, pero no de términos, ha de ponerse en relación con el 42.6 de la misma Ley que dispone "Cuando el número de las solicitudes formulada o las personas afectadas pudieran suponer un incumplimiento del plazo máximo de resolución, el órgano competente para resolver, a propuesta razonada del órgano instructor, o el superior jerárquico del órgano competente para resolver, a propuesta de éste, podrán habilitar los medios personales y materiales para cumplir con el despacho adecuado y en plazo. Excepcionalmente podrá acordarse la ampliación del plazo máximo de resolución y notificación mediante motivación clara de las circunstancias concurrentes y solo una vez agotado todos los medios a disposición posibles". 
terminado (el 49), como la ampliación del plazo total de duración del procedimiento (el 42.6). La UNED con base en el primero amplia correctamente el plazo de alegaciones de los interesados, pero lo aplica incorrectamente de forma extensiva cuando amplía el plazo total de duración del procedimiento de lesividad en mes y medio más"s

\section{RECAPITULACIÓN}

Puede decirse que, en principio, si se prevé en la legislación autonómica y en la Ley estatal 30/1992 la ampliación de plazos de duración máxima de los procedimientos, es porque estamos ante una posibilidad abierta que cumple una finalidad determinada. El quid es observar si se cumplen los presupuestos propios de los preceptos aplicables.

3 Añade esta sentencia: "Y esta última ampliación es la que considera esta Sala que no es posible en un procedimiento de lesividad como el que nos ocupa por las siguientes razones:

a) Porque no puede otorgarse la prórroga si con ello se perjudican los derechos de tercero. En este supuesto de lesividad es claro que, estando en el primer plano de la contienda el interés de la Administración y el interés público, los terceros son los Vicerrectores demandados y puesto que el plazo de tres meses de caducidad corre en su favor, cualquier ampliación de ese término como la que acaeció les perjudica claramente, pese a que se quiera justificar tal ampliación en los beneficios inmediatos que para ellos tendría el mayor plazo para alegar. Puesto que un beneficio de este tipo queda sin efecto cuando hay en juego un beneficio mayor a más largo plazo, que es la "perención" de un procedimiento que les perjudica de forma evidente al abrir la posibilidad de anulación de un acto favorable de reconocimiento de un complemento.

La "perención" por paralización de dicho procedimiento hubiera permitido a los particulares afectados liberarse de un procedimiento iniciado de oficio y que podría producirles efectos desfavorables.

b) Por otro lado, el artículo 49 invocado repetidamente por la UNED exige (al igual que el 42.6) que las circunstancias aconsejen la ampliación del plazo, y aunque en principio pudiera parecer por las argumentaciones de la Administración que era imposible la notificación del procedimiento y el transcurso del plazo de alegaciones de cada interesado en el término de tres meses, no ha quedado demostrado de forma totalmente evidente que no hubiese posibilidad de cumplir con ese único trámite la audiencia por quince días como máximo y diez como mínimo, que hay que cumplimentar en este procedimiento de lesividad desde su inicio, según el número 2 del artículo 103 en relación con el 84. Lo que ha hecho la Administración es complicar más aun el procedimiento al tener que notificar hasta cuatro acuerdos, en vez de solo uno: el inicio del expediente, el plazo de alegaciones, luego la prórroga en ocho días para las mismas, y posteriormente la ampliación del término del procedimiento porque a su entender no consta la totalidad de los acuses de recibo del acuerdo de ampliación anterior; acuerdos que se adoptaron si la justificación mínima cuando precisamente parece que lo más dilatorio era notificar cada uno de ellos a cada uno de los interesados.

Por lo demás, tales ampliaciones no parecen justificadas en absoluto cuando se desprende de los acuses de recibo de los interesados que obran en el expediente que el demandado que más tarde recibió la notificación de la comunicación de 1 de septiembre de 1999 sobre el plazo de alegaciones lo fue Sr. R. M. el 9 de octubre, cuando había sido ya notificado de la apertura del expediente el 3 de agosto anterior (folio 149) y todos los demás tenían en su poder el traslado para la audiencia desde primeros de septiembre. Por lo que incluso el que más tarde lo recibió hubiera cumplimentado su plazo máximo de audiencia antes de los tres meses.

Es más, según el artículo 42.6 la ampliación del plazo de resolución se regula como excepcional, es decir sino queda más remedio y solo una vez que se hayan agotado todos los medios a su disposición posibles, circunstancia que no se ha demostrado en absoluto, así como tampoco las condiciones de excepcionalidad. Y ello es así por cuanto que un procedimiento en marcha es un elemento potencialmente distorsionador de las situaciones jurídicas consolidadas". 
Podríamos recapitular en concreto sobre aquellos casos en que una ley autonómica prevé la ampliación del plazo máximo para resolver de los procedimientos. En estos casos hemos visto cómo se ha podido entender aplicable la ley autonómica, siempre que se expresen las razones que justifican dicha ampliación (y siempre que no haya existido una falta de diligencia por parte de la Administración en las actuaciones precedentes). Pero no es absolutamente descartable que los órganos jurisdiccionales examinen el supuesto considerando la Ley 30/1992. A su vez en tal caso, y en general el supuesto se puede examinar desde el punto de vista del artículo 42.6 de dicha Ley 30/1992, o ampliación del plazo máximo para resolver, exigiendo el recurso a este precepto el cumplimiento de las condiciones rigurosas y excepcionales que hemos estudiado.

La segunda opción es que se aplique en el caso concreto, por los órganos jurisdiccionales, el artículo 49 de la Ley 30/1992, siguiendo la jurisprudencia del Tribunal Supremo, que lo admite como base jurídica para la ampliación del plazo máximo para resolver con unas condiciones de aplicación no tan estrictas, pero con un régimen de ampliación del plazo menor prolongado. Puede aconsejarse (a la Administración) aplicar por cautela el plazo más breve de los que puedan resultar aplicables en el caso concreto.

Echamos, pues, en falta mayor certeza y seguridad jurídica, problema que se origina por el modelo de Estado y la proliferación de normas existentes. Lo normal es que existirá base para la ampliación pero no debida certeza, ya que, por sus características, quedamos sometidos a la apreciación subjetiva del intérprete judicial en el sentido expuesto de que pueda entender aplicable sólo la norma autonómica, o que pueda entender incluso aplicable el artículo 49 de la Ley 30/1992, o que pueda entender aplicable el artículo 42.6 en cuyo caso no es fácil superar la prueba de legalidad. $Y$ siempre bajo el telón de fondo de que, si se entiende improcedente la ampliación del plazo de duración máxima del procedimiento, se produciría caducidad y, según el caso, incluso, prescripción. 